\title{
Availability of Support and Services for Aural Rehabilitation of Children with Hearing Impairment in Punjab - A Survey of Parental Perception
}

\author{
Hina Noor ${ }^{*}$ \\ Manzoor Arif ${ }^{* *}$
}

\begin{abstract}
Involvement of parents in rehabilitation process is of vital importance. Parental perception and satisfaction from the available support and services are the indicators of their (un)met specific needs. The objectives of the study were to assess the parental perception about the level of available support from different personnel involved in the process of aural rehabilitation and to highlight the parental needs and recommendations for aural rehabilitation of children with hearing impairment (HIC). A survey was conducted from October 2014 to January 2015 to collect demographic data, information about level of support of different personnel as received by the parents, their opinion and recommendation about further required support. The sample comprised of 30 government special education institutes from which 308 questionnaires, filled by the parents of the HIC studying in these institutions were received back. The results highlighted the poor educational and income level of the parents, increasing incidence of hearing impairment in the families of HIC, lack of available support from personnel involved in aural rehabilitation and documented parental demands and recommendations. It was concluded that future planning of provisions for aural rehabilitation may be more effective, if aligned with the requirements and preferences expressed by parents of HIC.
\end{abstract}

Keywords: Aural rehabilitation, hearing impairment, parental perception.

\footnotetext{
${ }^{*}$ Lecturer, Allama Iqbal Open University \& Ph. D Scholar, Foundation University, Email: hina_imran78@yahoo.com

${ }^{* *}$ Professor, Bilqees college of Education, Email: zzeeshan@gmail.com
} 


\section{Introduction}

Aural rehabilitation services are the dire need of all those suffering from hearing loss, especially for those having severe and profound hearing loss. According to Ross (1997) aural rehabilitation involves 'any device, procedure, information, interaction, or therapy which lessens the communicative and psychosocial consequences of a hearing loss'. Wade \& De Jong (2000) presented the structure of rehabilitation as consisting of a multidisciplinary team of people having relevant skill and knowledge and involved in re-education of patient and family with an aim to maximize the social participation of the patient in the society as well as to minimize the pain and distress experienced by the patient and his/her family. In case of HIC, the success rate in social engagement and purposeful occupation is extremely dependent on the communication potentials of the individuals which are revived through aural rehabilitation services. Children with successful auditory, speech and language training tend to be successfully included into hearing society (Erber, 1982). Factors that might affect therapeutic outcomes in aural rehabilitation of HIC are the type and degree of hearing loss, age of onset of the loss affecting behavioural and linguistic needs of the individual, differences demanding individual or group therapy approaches, socioeconomic status determining capacity to purchase available products and services and the culture influencing interaction between hearing impaired individual and practitioner (Tye Murray, 2014).

Tucci, Merson and Wilson (2010) estimated that 50\% of the hearing loss can be prevented but financial resource allocation for early detection, rehabilitative and prevention is not adequate. Moreover, local social attitudes, believes, customs, and cultural bias are other contributing factors for the delay in diagnosis. Olusanya, Neumann \& Saunders (2014) reported that almost in all developing countries, incidence of congenital hearing loss is three times higher than the developing countries and priority should be given to primary prevention. It is stated that out of those who can get benefit from hearing aids/technology, only less than 3\% actually receive it (WHO, 2010; McPherson, 2011). Basavaraj (2008) commented about production of cost effective indigenous hearing aids in India and distribution of free or subsidized hearing aids by the government, but the distributed aids were mostly of body worn type. The author highlighted the acute shortage of personnel associated with rehabilitation process e.g. audiologists, earmould technicians, and hearing aid repair technicians. All of the above 
mentioned studies highlighted the dearth of available services regarding initiation of aural rehabilitation programs for $\mathrm{HIC}$ in developing countries including Pakistan.

Early identification of hearing loss and use of hearing technology/aids are just the first steps of the whole rehabilitation process because only access to auditory cues does not automatically leads to improvement in language abilities. Extensive practice is required to get the expected benefits of these hearing aids in the form of listening and speaking skill development. There is growing evidence that if these rehabilitation practices are accompanied with parental engagement in the child's rehabilitation process, it often leads to improved language acquisition (Des Jardin \& Eisenberg, 2007; Moeller, 2000; Zaidman-Zait $\&$ Young, 2007). The level of parental involvement in rehabilitation process affects the cognitive and psychosocial development of the HIC as they are the first ones to detect any discrepancy in the developmental aspects of their children thereby dictating the quality of their life (Dworkin, 1993; Flexer, 1994).

Parental awareness and education regarding childhood hearing impairment is of significant importance for the success of any screening, diagnostic and rehabilitation program in developing countries. In Pakistan, a study regarding parental awareness about auditory performance of their hearing impaired children who were receiving regular speech therapy and to assess their participation level in auditory skill development of their children with hearing impairment was conducted by Bano (2008). The results indicated that most of parents were using sign language as the mode of communication with HIC and $90 \%$ of them had never used any activity or game for improvement in auditory skill development. The researcher highlighted the lack of parental awareness about the importance of development of auditory skills for their children and the impact of aural rehabilitation on the lives of HIC. The author stressed on development of individually referenced performance measures to monitor the effectiveness of medical, audiological, instructional and communication interventions. Provision of an enriched auditory environment and training of teachers and parents regarding the auditory skill development were further recommendations of the author.

The parents of a child without disabilities have a responsibility to fulfill the daily needs of their children in addition to providing the environment appropriate for his/ her healthy growth and development. 
But parents of a disabled child are in charge of some additional responsibilities, such as collaborating in rehabilitation programs targeting specific skill development in the deficient area. Therefore, parents of the children with disabilities are in want of some additional support to fulfill their additional responsibilities (Emerson, 2003; Roberts \& Lawton, 2001). It is assumed that if the additional support required by these parents is not provided to them, it may affect their motivation and involvement level for achievement of the specified rehabilitation targets. Lederberg and Golbach (2002) reported that parents of deaf children rely greatly on professionals as sources of support. Palsdottit (2007) reported that support is of vital importance for the parents of HIC but access to the support from professionals and others may be limited. Parents are no doubt the key persons responsible for continuity of the rehabilitation program therefore an assessment of parental needs for information, guidance, support and collaboration is necessary, otherwise it may undermine the effectiveness of any intervention cum rehabilitation program. The author could not find any regional or local survey conducted to assess the extent of support services available to the parents in order to decide upon their needs. Therefore the study aimed to assess the extent of support for aural rehabilitation, available to the parents of HIC studying in special education institutions of Punjab. The survey was planned with the objectives to obtain the demographic data, to assess the parental perception about support services available to them at the time of diagnosis and during primary schooling of HIC and to obtain the parental opinion about their unmet needs and recommendations for aural rehabilitation of HIC in Punjab. Following research questions were targeted to explore the phenomenon.

1. When screening or diagnosis of hearing impairment was carried out?

2. Which of the personnel involved in aural rehabilitation were available to the parents at the time of diagnosis, during primary school years and in the last six months?

3. What was the level of support of personnel available to the parents?

4. Which of the professionals are still demanded by them for aural rehabilitation?

5. What are their recommendations regarding aural rehabilitation of their children? 


\section{Methodology}

Following Methodology was adopted:

\section{Research Design}

The study was descriptive in nature as it better serves to explore "what is" and allows collection of both quantitative and qualitative information. It was a survey with the following research design.

\section{Participants}

Twenty-seven special education institutions run by Directorate of Special Education, Punjab were selected as a cluster in such a way that one higher secondary school, one middle/primary school and one centre catering children with four major disabilities i.e. visual impairment, hearing impairment, mental retardation and physical impairment, was selected from nine divisions of Punjab. The three degree colleges for the HIC in Punjab were also included in the sample to have a total of 30 institutions. In the second stage of sampling, 20-30 parents of HIC studying in these institutions from pre-school to graduation level were randomly selected with the help of a focal person serving in each institution. The survey questionnaires were mailed to the focal persons after getting their consent to be held responsible for delivery and collection of the questionnaires from these parents and sending back to the researcher.

\section{Instrument}

A Questionnaire was developed for the parents of the HIC studying in special education schools of Punjab. Items were constructed section wise. Open ended items of the first section dealt with general information about the parents of HIC. Second section comprising of two closed type and two open ended questions dealing with the prevalence of hearing impairment in family and history of diagnosis of hearing impairment to reflect the screening and diagnostic facilities available. Closed and Likert scale type items were included in the next section dealing mainly with communication status of the HIC to estimate the impact of available provisions for aural rehabilitation of the HIC on communication capabilities of these children. Last section of the questionnaire was having closed type and Likert scale type items to assess the level of 
support of different personnel available to the parents. The level of available support from the list of personnel involved in the process of rehabilitation was checked at the time of diagnosis, during primary school years and in the last six months along with the parental demands cum needs about the required support of any professional at all mentioned time periods. This section also contained an open ended question to document the problems faced by the parents and their recommendations for aural rehabilitation of their children.

\section{Reliability and Validity}

Pilot testing was done with the help of 30 randomly selected parents of the HIC studying in National Special Education Centre for HIC, Islamabad. Content validity was checked with the help of parental opinion form attached with the questionnaire. As recommended by the parents, Urdu translated version of the questionnaire was developed. Questionnaire's reliability via Cronbacks alpha was checked and found to be at 0.88 .

\section{Data Collection and Analysis}

One focal person serving in the selected institutions was selected purposively to be held responsible for the delivery and collection of questionnaires to the randomly selected 20-30 parents of the HIC studying in different classes from pre-school to graduation level, as the case of individual institution permitted. All focal persons were contacted and guided again and again to get the best responses from the targeted population. Data analysis was done mainly by calculating simple percentages. Likert scale analysis was done by finding the mean support of each personnel available to the parents at the time of diagnosis and during primary school years. ANOVA was used to compare the mean difference between the support level of different personnel involved in aural rehabilitation both at the time of diagnosis of hearing impairment and during primary school years. The qualitative data obtained about problems faced by the parents and their recommendations was analyzed with the help of NVivo Pro 11. The responses were coded against the themes of provisions for aural rehabilitation. The responses not directly linked with themes were coded against others. 


\section{Results}

The response rate was $62 \%$ as out of 495,308 filled questionnaires were received back. Data was obtained from the parents of both hearing impaired boys and girls, out of which 59\% were the parents of girls and $40 \%$ were the parents of boys. Data about parental experiences and personal views was having rich diversity as HIC belonging to the varied age ranges were almost equally distributed. Punjabi was the main language of $47 \%$ HIC's families. The data revealed that the majority of the parents of HIC were poor, not well qualified and belonging to lower skill level occupation or government job as explained below.

Table 1

Parental Education, Employment and Income Level

\begin{tabular}{|c|c|c|c|c|c|c|c|}
\hline $\begin{array}{l}\text { Educational } \\
\text { level }\end{array}$ & $\begin{array}{l}\% \\
\text { father }\end{array}$ & $\begin{array}{l}\% \\
\text { mother }\end{array}$ & $\begin{array}{l}\text { Employment } \\
\text { status }\end{array}$ & $\begin{array}{l}\% \\
\text { father }\end{array}$ & $\begin{array}{l}\% \% \\
\text { mother }\end{array}$ & $\begin{array}{l}\text { Monthly } \\
\text { Income }\end{array}$ & $\%$ \\
\hline Illiterate & 9.1 & 18.2 & Skilled/ labour & 31.6 & 1.0 & Up to 5,000 & 2.3 \\
\hline Below matric & 18.5 & 26.6 & & & & Up to 10,000 & 26 \\
\hline Matriculation & 23.4 & 15.9 & Govt. Servant & 26.2 & 4.2 & Up to 15,000 & 26.6 \\
\hline Intermediate & 13.6 & 4.5 & & & & Up to 20,000 & \\
\hline Bachelor & 12 & 4.2 & Private Job & 7.8 & 1.0 & Up to 25,000 & 14 \\
\hline Master & 4.9 & 2.9 & Abroad & 1.6 & 49 & Up to 30,000 & 7.1 \\
\hline \multirow[t]{4}{*}{ No response } & 18.5 & 27.6 & No response & 32.8 & 44.8 & Up to 50,000 & 8.1 \\
\hline & & & & & & $>50,000$ & 7.1 \\
\hline & & & & & & No response & 1.6 \\
\hline & & & & & & & 7.1 \\
\hline
\end{tabular}

Poor parental and educational level indicates the notion of increasing financial and technical support level from the government and professionals for aural rehabilitation of HIC. It was revealed from the data that the incidence of another person with hearing impairment in the families of HIC was quite high and the most common deaf family members were the siblings of HIC. Hearing impairment was mainly present since birth but majority of the parents of HIC did not report the exact age of diagnosis of the disability as shown in table no 2 . 
Table 2

Incidence and Diagnosis of Hearing Impairment in HIC Families

\begin{tabular}{llllll}
\hline $\begin{array}{l}\text { Incidence of } \\
\text { H.loss in family }\end{array}$ & $\%$ & $\begin{array}{l}\text { When the child } \\
\text { become deaf }\end{array}$ & $\%$ & $\begin{array}{l}\text { When H.loss } \\
\text { was diagnosed }\end{array}$ & $\%$ \\
\hline Father & 3.8 & By Birth & 68.4 & At Birth & 6.5 \\
Mother & 3.2 & Birth - 6 Week & 7.2 & At 6 - Weeks & 1.3 \\
Brother & 24.6 & 6 Week - 6 Month & 3.3 & At 6- Months & 1.0 \\
Sister & 22.7 & 7-11 Months & 8.1 & At 12 - Months & 2.0 \\
Any other & 8.4 & 12-24 Months & 2.9 & At 18 - Months & 0.7 \\
HIC with other & 7.7 & Above 24 months & 4.8 & At 24- Months & 2.0 \\
Disability & & No response & 5.5 & No response & 86.9 \\
\hline
\end{tabular}

The apparent high incidence of having another deaf family member by HIC needs to be addressed properly and further government sponsored studies may be carried out to estimate the future requirements of services for aural rehabilitation of HIC. Moreover the parental unreported information about the exact age of diagnosis may indicate the lack of available facilities for screening, diagnosis and referral services.

Parents were asked about the services they received during the last six months. Overall 499 responses were entered by 308 parents, as few of them mentioned the availability of more than one professional to them in the last six months. After teachers, the most available persons in the last six months were speech therapist, audiologist and psychologists. Professionals that were still demanded by the parents were the audiologist and the speech therapist.

As far as parental opinion about the extent of available support from different personnel involve directly or indirectly in aural rehabilitation of HIC is concerned, the following bar graphs are plotted with y-axis having the percentages of their opinion ranging between very less to very much available support. All the personnel involved in different stages of aural rehabilitation process are shown on $\mathrm{x}$-axis. Blue bar represents the cumulative percentage of very much and much support and green bar also represents the combined percentages of very less and less support level. The red bar, representing the percentage of average level of support is in the middle. 


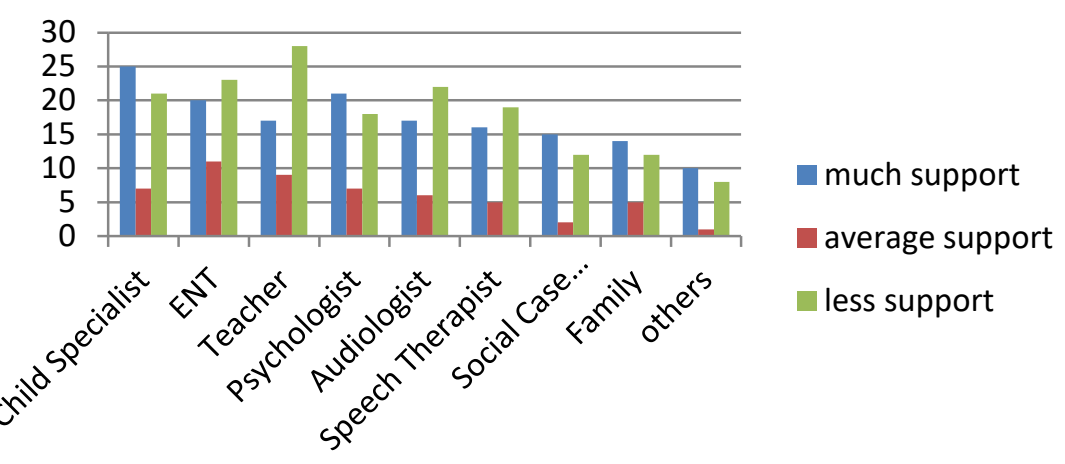

Figure 1: Availability of support from different personnel at the time of diagnosis

Figure 1 shows the level of percentage support by the personnel involved in aural rehabilitation, at the time of diagnosis. More parents reported less available support and services from ENT specialist, teacher for the deaf, audiologist and speech therapist, whereas more child specialist, psychologist, social case worker and family members were reported to be providing much support by the parents.

The same personnel were ranked by the parents to report about the level of support and services received by them during primary school years. Their responses are plotted below in figure 2

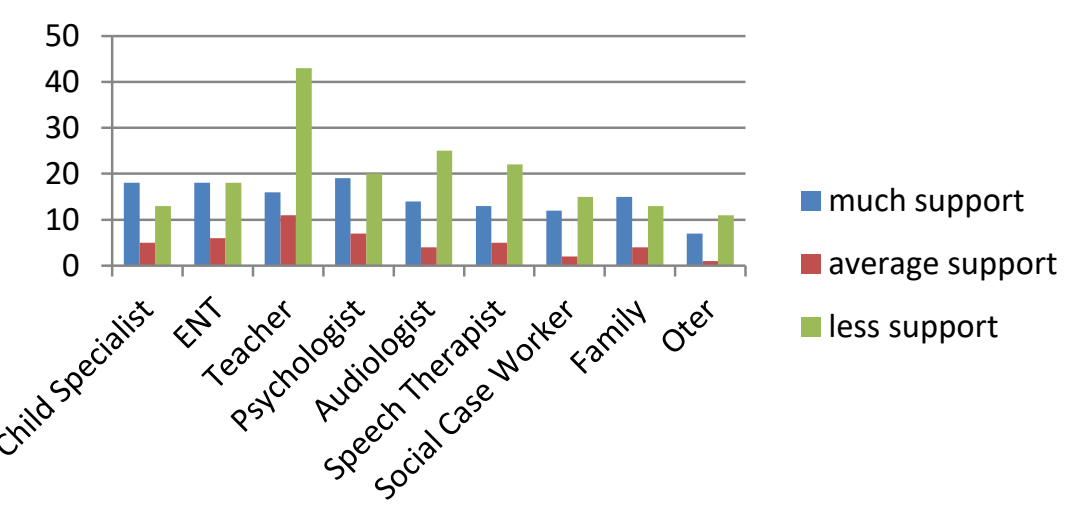

Figure 2: Availability of support from different personnel during primary school years

Figure 2 shows the level of percentage support and services of different personnel involved in the process of rehabilitation, during primary school years. Only child specialist and family members were 
reported to be as providing much support and all other personnel involved in aural rehabilitation were reported to be providing less support by the parents.

It is clear from figure 1 and 2 that with the passage of time there was a decrease in level of the support and services provided by different professionals. Moreover at the time of diagnosis as well as during primary school years, the level of support and services of the personnel involved indirectly in the rehabilitation of HIC (doctors, psychologist, social case worker and others), was almost satisfactory. But the persons with complaint of the less support were the audiologists, speech therapists and teachers who are considered as the active agents of aural rehabilitation of children with hearing impairment.

Mean support of different personnel, available to the parents at the time of diagnosis and during primary school years was found to be significant at $95 \%$ confidence interval as shown in table 3 . Moreover the difference between total mean support level at the time of diagnosis (2.83) and during primary school years (2.65) further supported the increasing parental complaints with the passage of time.

Table 3

Mean support level of different personnel available to the parents

\begin{tabular}{|c|c|c|c|c|c|c|}
\hline \multirow[t]{3}{*}{ Personals } & \multicolumn{3}{|c|}{ At the time of diagnosis } & \multicolumn{3}{|c|}{ During primary school years } \\
\hline & Mean & $\begin{array}{l}95 \% \text { co } \\
\text { interval }\end{array}$ & $\begin{array}{l}\text { fidence } \\
\text { or mean }\end{array}$ & Mean & $\begin{array}{l}95 \% \text { co } \\
\text { interval }\end{array}$ & $\begin{array}{l}\text { lence } \\
\text { mean }\end{array}$ \\
\hline & & $\begin{array}{l}\text { Lower } \\
\text { bound }\end{array}$ & $\begin{array}{l}\text { Upper } \\
\text { bound }\end{array}$ & & $\begin{array}{l}\text { Lower } \\
\text { bound }\end{array}$ & $\begin{array}{l}\text { Upper } \\
\text { bound }\end{array}$ \\
\hline Peadiatrician & 2.88 & 2.62 & 3.13 & 2.72 & 2.41 & 3.03 \\
\hline ENT specialist & 2.82 & 2.58 & 3.05 & 2.89 & 2.60 & 3.17 \\
\hline Teacher for deaf & 2.55 & 2.32 & 2.79 & 2.28 & 2.07 & 2.48 \\
\hline Edu. psychologist & 3.07 & 2.80 & 3.34 & 2.94 & 2.67 & 3.22 \\
\hline Edu. audiologist & 2.81 & 2.50 & 3.11 & 2.47 & 2.19 & 2.75 \\
\hline Speech therapist & 2.79 & 2.49 & 3.10 & 2.57 & 2.28 & 2.86 \\
\hline Family & 3.00 & 2.66 & 3.34 & 2.98 & 2.63 & 3.33 \\
\hline
\end{tabular}

Significance of the difference in individual mean support of different personnel was tested with ANOVA. It is clear from table 4 that at the time of diagnosis, the $\mathrm{P}$ value (.16) was greater than $\alpha$ value (.05) thus the null hypothesis was not rejected and it was concluded that overall there was no significant difference between mean support levels of 
different personnel at that time. But during primary school years, the $P$ value (.00) was less than $\alpha$ value (.05) thus the null hypothesis was rejected and it was concluded that overall there was significant difference present between mean support levels of different personnel at that time.

Table 4

\begin{tabular}{|c|c|c|c|c|c|c|}
\hline $\begin{array}{l}\text { Specific time } \\
\text { period }\end{array}$ & Levels & $\begin{array}{l}\text { Sum of } \\
\text { Squares }\end{array}$ & $D f$ & $\begin{array}{l}\text { Mean } \\
\text { Square }\end{array}$ & $f$ & Sig. \\
\hline \multirow[t]{3}{*}{ At diagnosis } & Between Groups & 25.192 & 6 & 4.199 & 1.528 & .166 \\
\hline & Within Groups & 2783.804 & 1013 & 2.748 & & \\
\hline & Total & 2808.996 & 1019 & & & \\
\hline \multirow{3}{*}{$\begin{array}{l}\text { During primary } \\
\text { school }\end{array}$} & Between Groups & 65.340 & 6 & 10.890 & 4.118 & .000 \\
\hline & Within Groups & 2515.112 & 951 & 2.645 & & \\
\hline & Total & 2580.452 & 957 & & & \\
\hline
\end{tabular}

Although the difference in mean support received by the parents, at the time was diagnosis of hearing impairment was not significant but the multiple comparison analysis revealed that there was a significant difference between the support level of teachers and psychologists ($\left..514^{*}\right)$ and that of teachers and family $\left(-.446^{*}\right)$ at 0.05 level of significance. The multiple comparison analysis of the mean support level of the personnel during primary school years further revealed that there was a significant difference between the support level of teachers and psychologists $\left(-.610^{*}\right)$, teachers and family $(-.704 *)$, teachers and ENT ($\left..610^{*}\right)$ and that of the teachers and pediatricians $\left(-.446^{*}\right)$ at 0.05 level of significance. All these significant differences of teacher's support level with other professionals indicated that teachers were not providing the support and services as required by the parents.

$25-33 \%$ parents expressed their wish of availability of services of some professionals at the time of diagnosis as well as during primary school years and the most demanded professionals were speech therapists and audiologists. Only $23 \%$ parents attempted to answer the open-ended questions of the questionnaire related to the problems faced by them and their demand from the government. Only those parental comments about the problems faced by them and their recommendations cum demands were mentioned that showed the frequency of at least five times. Summary of parental opinions and problems faced by them is as follows: 
- Educational methodology is not correct.

- The teachers are neglecting HIC needs.

- Provision of milk had been stopped.

- Facilities are required for mental and physical growth of the child.

- Employment opportunities for HIC are scarce.

- Hospitals are not treating HIC properly.

- They had missed the excellence of speech therapist and audiologist.

- Even a position holder child can't write a single sentence correctly.

- Lack of money is main hurdle in purchasing aid.

- We also feel lack of moral support from family.

- All HIC could not get a cochlear implant then what is the solution for those children.

Summarized form of parental recommendations cum demands and areas demanding immediate attention from the government is as follows:

- Financial support for medical intervention

- Provision of hearing aids and accessories

- Infrastructure development of institutes

- Provision of books and more specialized teachers for deaf

- Appointment of a speech therapist and audiologists in institutions

- Appropriate treatment plans and free monthly medical checkup in all hospitals.

- Speech therapy and auditory facilities and provisions

- Enhancement of transportation Facilities

- Focus on moral values in curriculum development

- Job placement facilities.

- Separate doctors for special persons in all hospitals

\section{Discussion}

A study by Naeimeh, Pedram, Nasrinet et. al. (2009) emphasized that key of intervention program for HIC is to establish a communication system for the child and for their parents. Aural rehabilitation programs are feasible as well as effective for enhancement of activity and participation of the hearing impaired in developing country.

An important finding of the study that the incidence of hearing impairment in families was increasing is consistent with results of Barnett (2002) that approximately $9 \%$ of the US population is with hearing impairment and the prevalence of the loss is increasing. Again the percentages of deaf parents (3.8\% fathers and 3.2\% mothers) reported 
in the current research are very close to the estimate of Mitchell \& Karchmer (2004) that 5\% HIC were having at least one deaf parent.

The findings of income per month in India are near to the researcher's findings, which reported that $93 \%$ deaf families were having less than $102 \$$ per month (Rout \& Uday 2010) and current research reported that $26 \%$ parents were having monthly income up to $99 \$$ and $26 \%$ were having up to $148 \$$ approximately.

The 2006 legislature directed the Washington State institute for public policy, to arrange a meeting of stakeholders in order to examine the strengths and weaknesses of educational services available to HIC. Current study's parental comments about the special education system for HIC are in agreement with the views of the stakeholders in Washington that the education system for hearing impaired is fragmented and inadequate. And parental suggestions are also similar to parents of $\mathrm{HIC}$ in Washington i.e. strengthening early intervention equipments, expanding resources for technology based supports, authority for coordination and improving teaching standards.

The return rate of the survey questionnaires was $62 \%$ which initially seems to be somehow deficient to generalize the results to the population, but the return rate was better than $31 \%$ return rate of the survey of parents of high and very high need deaf students in mainstream schools of New Zealand as reported by Mc Kee \& Smith (2003). Although the return rate was just average, but room for improvement is always there, especially a survey of stakeholders' recommendations which are likely to become part of future strategic plan, is liable to have a better response rate. As only $23 \%$ parents opted the two open-ended questions, so inclusion of closed choice items in questionnaires would have been more helpful to the researcher in getting more responses from parents.

The misconception by parents regarding oral versus manual communication was noted by the researcher during data analysis which was not evident before through pilot testing. The problem occurred due to ambiguity in the questionnaire faced by illiterate parents surveyed, and not by the majority of graduate parents of pilot testing.

Identical writing pattern was personally noticed by the researcher during the data entry indicating that may be the parental questionnaires were filled with the help of either a teacher of their child or the head of the institution. No doubt, it was helpful to illiterate parents, but the researcher suspects that this practice may be a source of a large number of no responses and a fewer recommendations made by parents. 


\section{Conclusion}

The support level of different professionals available to the parents, either at the time of diagnosis, during primary school years or in the last six months was slightly less than average and the professional with least level of support to the parents was the teacher for deaf. The majority of the parents who wished to have availability of different professionals' services demanded the availability of support and services from the audiologists and speech \& language therapists. The majority of the parents reported lack of money to purchase the aids etc. and lack of facilities in the special education institutions. Most of the parents of older HIC pointed out the scarce employment opportunities and the lack of skill oriented curriculum and training facilities. The majority of parents demanded quantitative as well as qualitative increase in current facilities as well as provision of hearing aid, financial support for maintenance of aid and medical intervention by the government. Parents also recommended curriculum changes like more focus on moral values, speech and language development and vocational training with job placement or internship facilities. Exploration of parental needs at different timings, in order to match them with services provided, is crucial for effective planning and decision making in the rehabilitation process. 


\section{References}

Bano, A. K. (2008). Parental awareness about auditory performance of their children with hearing impairment. Journal of Special Education,9, 1-7. Retrieved from http://specialsedu.blogspot.com/ 2011/01/parental-awareness-about-auditory.html

Barnett, S. (2002). Communication with deaf and hard-of-hearing people: A guide for medical education. Academic Medicine, 77(7), 694-700. Retrieved from https://www.ncbi.nlm.nih.gov/pubmed/12114142

Basavaraj V. (2008). Hearing aid provision in developing countries: An Indian case study. In McPherson B., Brouillette R. (Eds.), Audiology in developing countries (pp. 155-166). New York, NY: Nova Science.

DesJardin, J. L. \& Eisenberg, L. S. (2007). Maternal contributions: Supporting language development in young children with cochlear implants. Ear \& Hearing, 28(4), 456-469.doi:org/10.1097/AUD. 0b013e31806dc1ab

Dworkin, P. H. (1993). Detection of behavioral, developmental and psychosocial problems in pediatric primary care practice. Current opinion in pediatrics. 5(5), 531-6. Retrieved from https://www.ncbi. nlm.nih.gov/pubmed/7506962

Emerson, E. (2003). Mothers of children and adolescents with intellectual disability: social and economic situation, mental health status, and the self-assessed social and psychological impact of the child's difficulties. Journal of Intellectual Disability Research, 47(4-5), 385-99. doi: 10.1046/j.1365-2788.2003.00498.x

Erber, N. P. (1982). Auditory Training. Washington DC: Alex Graham Bell Assn for Deaf.

Flexer, C. (1994). Facilitating hearing and listening in young children (1st ed). San Diego: Singular Publishing Group.

Lederberg, A. R., \& Golbach, T. (2002). Social support and parenting stress in hearing mothers of deaf preschoolers: A longitudinal study. Journal of Deaf Studies and Deaf Education, 7, 330-345. 
McKee, R. L., \& Smith, E. (2003). Report on a survey of parents of 'high' \& 'very high needs' deaf students in mainstream schools. (Report No. 1) Deaf Studies Research Unit; Victoria University of Wellington. Retrieved from: https://www.victoria.ac.nz/lals/research/ projects/publications/Report_1_Parents_Survey.pdf

McPherson, B. (2011). Innovative technology in hearing instruments: Matching needs in the developing world. Trends in Amplification, 15(4), 209-14. doi: 10.1177/1084713811424887.

Mitchell, R. E., \& Karchmer, M. A. (2004). Chasing the mythical ten percent: Parental hearing status of deaf and hard of hearing students in the United States. Sign Language Studies, 4(2), 138-163. Retrieved from https://www.researchgate.net/publication/236771867 Chasing the Mythical Ten Percent Parental Hearing Status of Deaf and Hard of Hearing Students in the United States

Moeller, M. P. (2000). Early intervention and language development in children who are deaf and hard of hearing. Pediatrics, 106(3), 1-9. Retrieved from http://pediatrics.aappublications.org/content/ $106 / 3 / \mathrm{e} 43$

Naeimeh, D., Pedram, B., Nasrin, Y., Farin, S., \& Roshanak, V. (2009). Oral communication development in severe to profound hearing impaired children after receiving aural habilitation. Acta Medica Iranica, 47(5), 363-367. Retrieved from http://acta.tums.ac.ir/index. php/acta/article/view/3608/3584

Olusanya, B. O., Neumann, K. J., \& Saunders, J. E. (2014). The global burden of disabling hearing impairment: a call to action. Bulletin of the World Health Organization, 92(5), 367-373. doi: org/10.2471/ BLT.13.128728

Palsdottit,K. (2009). Parents experience when their child is diagnosed with hearing loss (Master research thesis in Audiology). Gothenburg University Publications Electronic Archive. (130.241.16.4) http:// hdl.handle.net/2077/21246

Roberts, K., \& Lawton, D. (2001). Acknowledging the extra care parents give their disabled children. Child: Care, Health and Development, 27(4), 307-19. Retrieved from https://www.ncbi.nlm.nih.gov/ pubmed/11437835 
Ross, M. (1997). A retrospective look at the future of aural rehabilitation. Journal-Academy of Rehabilitative Audiology, 30, 11-28. Retrieved from http://www.audrehab.org/jara/1997/Ross, \%20\%20JARA, \%20 \%201997.pdf

Rout, N., \& Singh, U. (2010) Age of suspicion, identification and intervention for rural Indian children with hearing loss. Eastern Journal of Medicine, 15(3), 97-102. Retrieved from https://www. journalagent.com/ejm/pdfs/EJM 15397 102.pdf

Tucci, D. L., Merson, M. H., \& Wilson, B. S. (2010). A summary of the literature on global hearing impairment: current status and priorities for action. Otology \& Neurotology, 31(1): 31-41.doi: 10.1097/MAO. 0b013e3181c0eaec

Tye-Murray, N. (2014). Foundations of aural rehabilitation: Children, adults, and their family members. Cengage Learning.

Wade, D. T., De Jong, B. A. (2000), Recent advances in rehabilitation. BMJ: British Medical Journal. 320(7246), 1385-1388. Retrieved from https://www.ncbi.nlm.nih.gov/pmc/articles/PMC1118051/

World Health Organization. (2010). Millions of people in the world have hearing loss that can be treated or prevented. Retrieved fromhttp://www.who.int/pbd/deafness/news/Millionslivewithhearing loss.pdf?ua=1

Zaidman-Zait, A., \& Young, R. A. (2007). Parental involvement in the habilitation process following children's cochlear implantation: An action theory perspective. Journal of Deaf Studies and Deaf Education, 13(2), 193-214. doi: org/10.1093/deafed/enm051

\section{Citation of this Article:}

Noor, H., \& Arif, M. (2017). Availability of support and services for aural rehabilitation of children with hearing impairment in Punjab - a survey of parental perception. Pakistan Journal of Education, 34(2), 1-17.

Received on: October 28, 2016

Revised on: September 29, 2017

Accepted on: October 18, 2017 